\title{
A Study on Thermal and Electrical Conductivities of Ethylene-Butene Copolymer Composites with Carbon Fibers
}

\author{
Yasin Hamida, Petr Svoboda ${ }^{a}$, Dagmar Svobodovab
}

\begin{abstract}
a Department of Polymer Engineering, Faculty of Technology, Tomas Bata University in Zlin, Vavreckova 275, 76272 Zlin, Czech Republic

b Language Centre, Faculty of Humanities, Tomas Bata University in Zlin, Stefanikova 5670, 760 01 Zlin, Czech Republic
\end{abstract}

Keywords: Thermal conductivity, Electrical conductivity, Composite, Carbon fiber

\begin{abstract}
The electrical, mechanical and thermal conductivity of ethylene butene copolymer (EBC) composites with carbon fibers were studied. EBC/carbon-fiber composites can be utilized as an electro-mechanical material which is capable of changing it electric resistance with mechanical strain. Carbon fibers were introduced to EBC with different concentrations (5-25 $w t \%)$. The results showed that the addition of carbon fibers to EBC could increase the electric resistance up to 10 times. Increasing the load to $2.9 \mathrm{MPa}$ could increase the electric resistance change by $4500 \%$ compared $25 \%$ fiber sample with pure EBC. It is also noted that the electric resistance of the EBC/CF composites underwent a dramatic increase with raising the strain, for example, the resistance change was around 13 times more at 15\% strain in comparison to 5\% of strain; The thermal conductivity tests showed that the addition of carbon fibers could increase the thermal conductivity by 40\%, from 0.19 to 0.27 (Wm-1K-1). It was also observed that the addition of carbon fibers to EBC could increase the thermal conductivity.
\end{abstract}

\section{Introduction}

Polymer composite containing carbon fiber is wildly used in industry due to excellent thermal, electrical and mechanical properties they can be used as a flexible electric sensor according to high sensitivity to strain and low industrial costs [1-3]. Many researchers indicated that the electrical conductivity of the polymer/carbon-fibre composite could be influenced by its deformation [4-7]. This change highly responds to the size and direction of the carbon fiber. Slobodian et al., studied on the influence of deformation on electric resistance for Carbon Nanotube (CNT)/Polyurethane (PU) and found the increase in resistance and Gauge factor which is defines the sensitivity of strain as a relative resistance change divided by applied strain to explain the effect of applied preload on the increases of 
relative resistance change of CNT/PU composites with introducing the strain [7]. Previous works show that the electrically conductive composite can be used in real-time like electric skins, entertainment system, human health monitoring for Parkinson disease patients due to the high response of electrical resistance to strain[8]. Li et al., reported that a change of resistance of multiwalled carbon nanotube film can be used as an electric sensor as it is highly responding to the strain [9].

Nowadays studies have indicated that the addition of fiber to a polymer matrix could influence the thermal conductivity of the composites [10-13]. Svoboda et al., [10] reported that the thermal conductivity of ethylene-octane copolymer/graphite composite increased by $245 \%$ where the fillers was increased from 0 to $50 \mathrm{wt} \%$ due to the uniform distribution of the graphit fibers

In this research, the author tried to investigate the effect of loading on electro-mechanical properties of the ethylene-butene copolymer (EBC) and Carbon fiber (CF) under elongation/relaxation cycle with a variety of loads. Moreover, the influence of carbon-fibre material with thermal conductivity of EBC was investigated.

\section{Experiment}

Ethylene-butene copolymer with0 has density $0.862 \mathrm{~g} / \mathrm{cm}^{2}$, ultimate tensile strength $2.0 \mathrm{MPa}$, melt index $1.2 \mathrm{dg} / \mathrm{min}$ and tensile elongation $600 \%$ were purchased from DOW chemical company in USA. Carbon fiber was T700SC 12000-50C provided by Toray Carbon Fibers America Inc, USA. The tensile strength and modulus are $4900 \mathrm{MPa}$ and $230 \mathrm{GPa}$ respectively. The carbon fiber has $7 \mu \mathrm{m}$ thickness with a $1.8 \mathrm{~g} / \mathrm{cm} 3$ density and $2.1 \%$ strain. The thermal conductivity of CF is 0.0224 $\mathrm{Cal} / \mathrm{cm} \cdot \mathrm{s} .{ }^{\circ} \mathrm{C}$, while the electric resistivity is $1.6 \times 10^{-3} \Omega \cdot \mathrm{cm}$ indicated by TORAYCA ${ }$.

$\mathrm{EBC} / \mathrm{CF}$ was prepared using a two-roll mill for $5 \mathrm{~min}$ at $150^{\circ} \mathrm{C}$. Then, compression molding was used to prepare the sheets with a thickness of $1 \mathrm{~mm}$ at $10 \mathrm{MPa}$ with 5 min preheating and 6 min pressing, at $150{ }^{\circ} \mathrm{C}$. Finally, the dumbbell shaped films were prepared with a compression cutter for the test.

The electrical resistance change during strain-relaxation cycles were analyzed with a 7338 Sefram multimeter by using a two-point technique. The tests were done using a variety of stresses $(0.442$, $0.884,1.325,1.768$, and $2.219 \mathrm{MPa}$ ) with the strain and electric resistance change with time.

The Fitch (1935) method was used to determine the thermal conductivity of the EBC/CF composites [14], where the specimen is sandwiched between a warm source and a steady temperature metal disc 
as a heat sink. A schematic representation of the instrument used for thermal conductivity measurements is shown in Fig 1.

The process of measurement and the instrument are explained below. At first, the $5 \mathrm{~cm}$ diameter central brass cylinder $(\mathrm{CBC})$ was heated to $\mathrm{T}_{2}=45^{\circ} \mathrm{C}$ with the assistance of another chamber which was connected with a water indoor regulator by elastic hoses with a water thermostat with $0.1{ }^{\circ} \mathrm{C}$ accuracy; it took about 3 minutes to reach a suitable temperature. Then the hot chamber was quickly removed and the sample with a $5 \mathrm{~cm}$ diameter was placed on top of the $\mathrm{CBC}$ with the second brass cylinder on top of it with a weight of $100 \mathrm{~g}$, which was connected to a second water thermostat with the temperature set to $25^{\circ} \mathrm{C}$.

Heat was transferred from the hot $\mathrm{CBC}$ to the cold cylinder by passing trow the sample. The $\mathrm{CBC}$ temperature is reduced quickly. The $\mathrm{CBC}$ data were collected every $5 \mathrm{~s}$ for $30 \mathrm{~min}$ by a thermocouple which was associated with a National Instruments information obtaining hardware (NI USB-9211A, Portable USB-Based DAQ (Data Acquisition)) for Thermocouple software and using the computer through the USB port [15]. The data was analyzed using LabVIEW Signal Express 2.5.

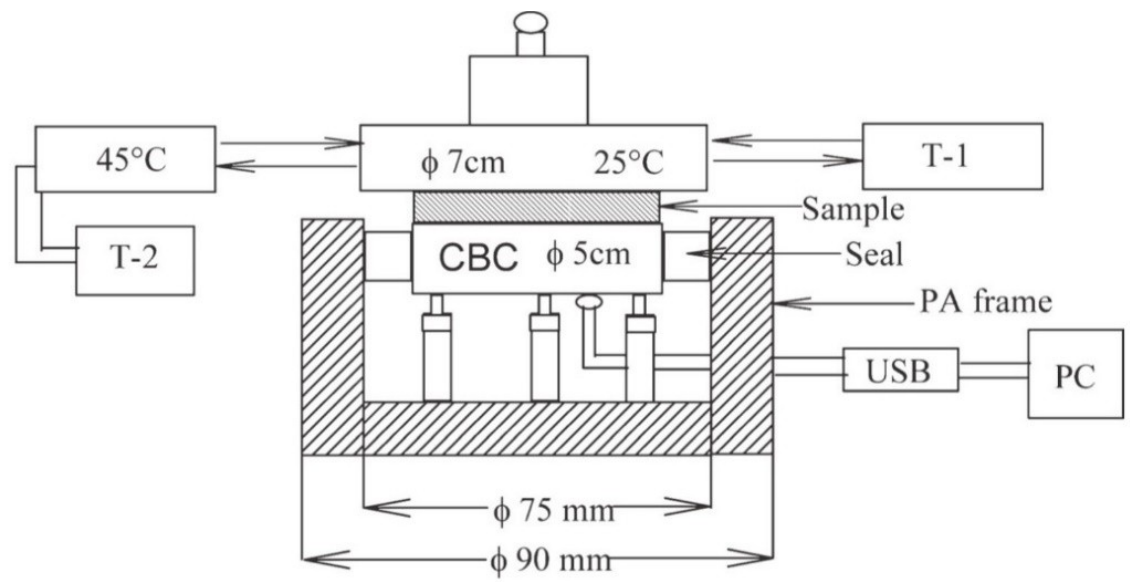

Fig. 1. Graphical outline of the device utilized for measurement of thermal conductivity

The $(\mathrm{EBC}) /(\mathrm{CF})$ films were melt welded (at $200^{\circ} \mathrm{C}$ ) with a thickness of $0.5 \mathrm{~mm}$ on the surface of microscop slide. Polarized optical Olympus RX41 microscope (Tokyo, Japan) was used to observe the structure of the composite.

\section{Results and discussions}

\section{Electrical conductivity}


Tensile deformation and gauge factors which is the ratio of relative change in electrical resistance $\mathrm{R}$, to the mechanical strain $\varepsilon$ of $\mathrm{EBC} /$ carbon-fiber composites were determined by a twopoint technique to measure the electric resistance as a function of the strain. In this research, the change in electrical resistance was defined as: [10]

$$
\Delta R=\frac{R-R_{0}}{R_{0}}
$$

Where

$R_{0}=$ the initial electrical resistance of the sample before the first elongation

$R=$ the resistance during elongation

The elongation is defined as:

$$
\varepsilon=\frac{L-L_{0}}{L_{0}}(2)
$$

Where $\mathrm{L}_{0}$ represents the initial length of the $\mathrm{EBC} / \mathrm{CF}$ specimen while $\mathrm{L}$ is the length during the stretching experiment.

The composite samples with the varitys concentrations of CF $(5,10,15,20$ and $25 \mathrm{wt} \%)$ were deformed by the tensile stress with increasing values of stress $(0.442,0.884,1.325,1.768$, and 2.219 $\mathrm{MPa})$ respectively.

Micrograph of optical microscopy from EBC carbon fiber for $15 \mathrm{wt} \%$ and $25 \mathrm{wt} \%$ can be seen in Figure 2.
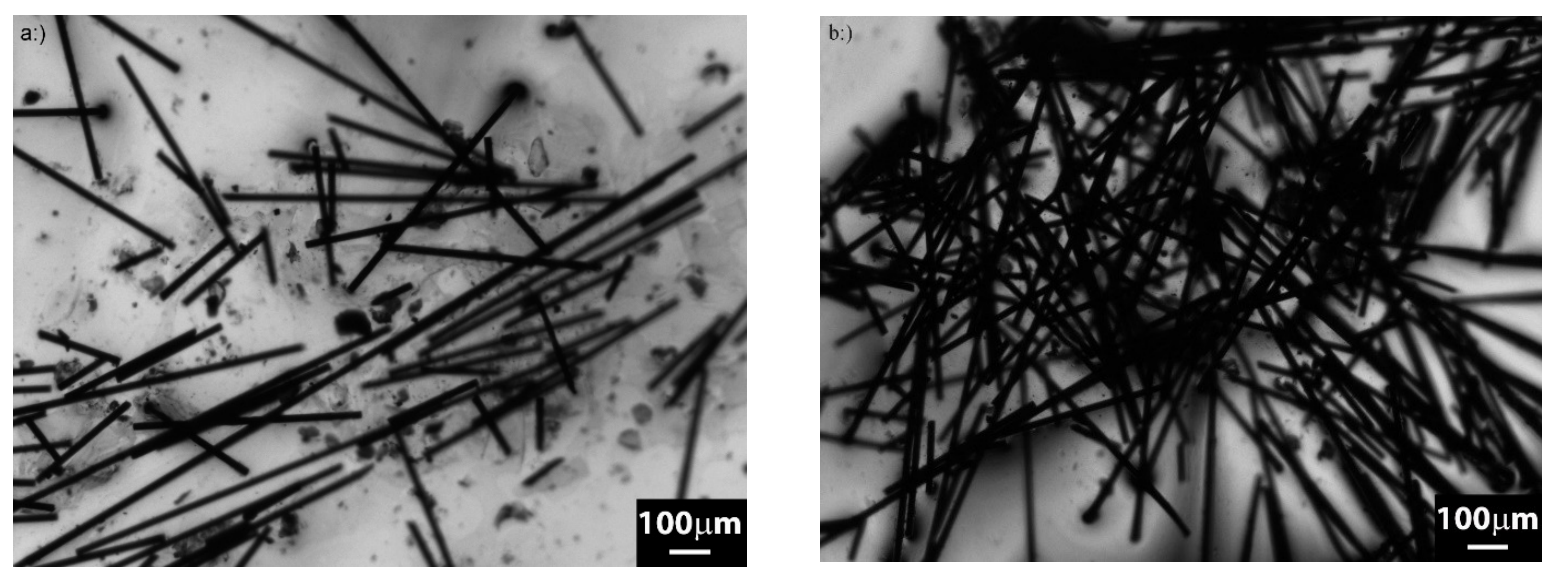
Fig. 2. Micrographs from optical microscopy (a) ethylene-butene -copolymer (EBC) and carbon fiber (CF) with $15 \mathrm{wt} \%$ (b) ethylene-butene copolymer (EBC) and carbon fiber (CF) $25 \mathrm{wt} \%$.

Figure 2 shows the fracture morphologies of EBC with $15 \mathrm{wt} \%$ and wt $25 \%$ of carbon fiber. The optical microscopy examination indicated that the fibers were homogeneously distributed in the EBC composites. It was also observed that at low fiber contents, $15 \mathrm{wt} \%$, there were fewer fibers lying on the surface in compare with the $25 \mathrm{wt} \%$ carbon fiber. The composite with $25 \mathrm{wt} \%$ carbon fiber had higher fiber agglomerates because of insufficient dispersion caused by self-association of excess filler[16].

The strain caused by tensile stress and change of electrical resistance was measured. The change of electric resistance of $\mathrm{EBC}$ with $5 \%$ and $10 \%$ of carbon fibers could not be measured. There being zero conductivity because of the low concentration of CF. It was also observed that, the EBC composite with $15 \%$ of carbon fiber had a low change of electrical resistance with a change of strain due to the low content of carbon fibers, that might be because of the lower amount of fiber and resistivity of carbon fiber during the deformation. Furthermore, it is observed in Figure 3 that EBC/CF with 25 $\mathrm{wt} \%$ resistance change is increasing with deformation, as increasing the connection between carbon fibers.[5,7,15]. The amount of fibers in EBC/CF $15 \mathrm{wt} \%$ is much lower than $25 \mathrm{wt} \%$ that could be measured only up to 0.884 MP. Figure 3 shows that five cycles increase of tensile strain up to 2.935 $\mathrm{MPa}$ for $25 \mathrm{wt} \%$ and four steps up to $1.768 \mathrm{MPa}$ for $15 \mathrm{wt} \%$ of $\mathrm{CF}$.
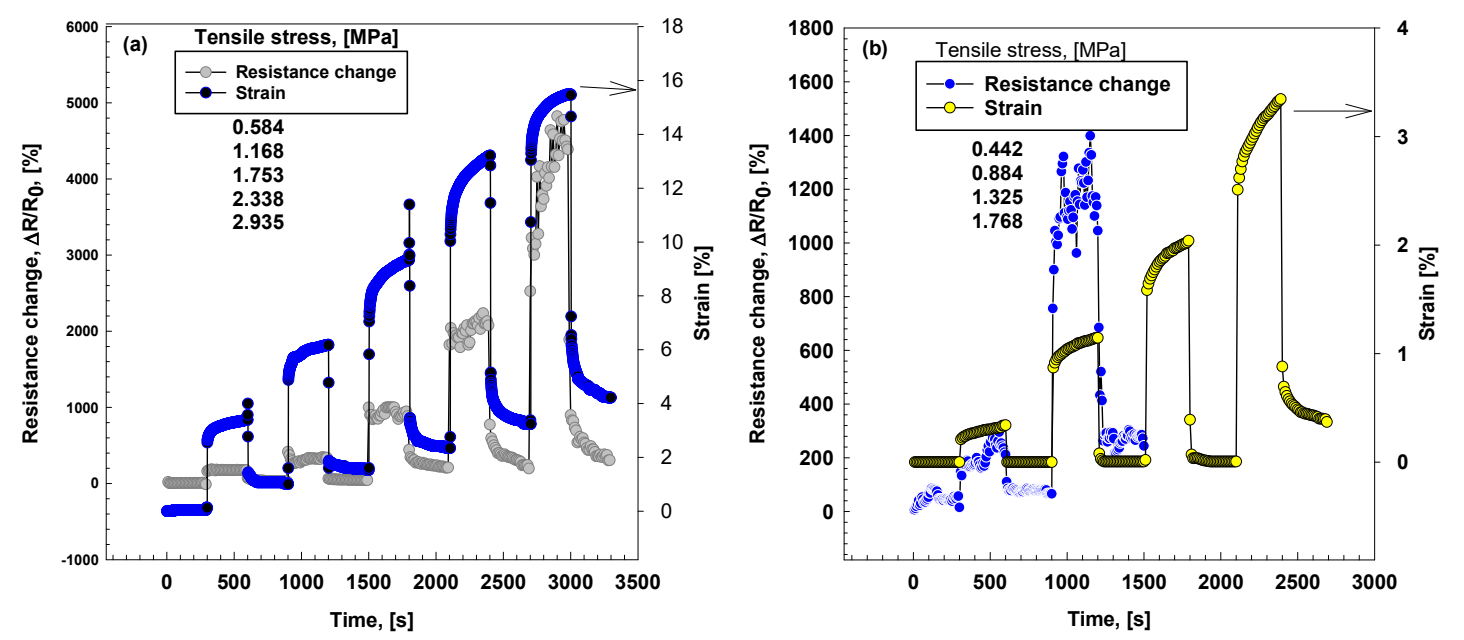
Fig. 3. relative resistance change, $\Delta \mathrm{R} / \mathrm{R}_{0}$, and the strain, $\varepsilon$, of a) $\mathrm{EBC} / \mathrm{CF} 25 \mathrm{wt} \%$ b) $\mathrm{EBC} / \mathrm{CF} 15$ wt $\%$.

By opening the circles in the graph, the relevant resistance changes while the values of strain are signified by solid circles. Figure 3 shows that $\mathrm{EBC} / \mathrm{CF} 25 \mathrm{wt} \%$ is conductive also at the peak strain of about $16 \%$ once the resistance change is about $4500 \%$.

The relative resistance increases with strain continually with no gap. It is no longer common in the case of the conductive particulate mixture when a point of very high resistance is touched the higher strain. Furthermore, the resistance of the mixtures returns almost to unload state to the value of 0 and 3 percent for $15 \mathrm{wt} \%$ and $25 \mathrm{wt} \%$ respectively as can see in Figure 4.

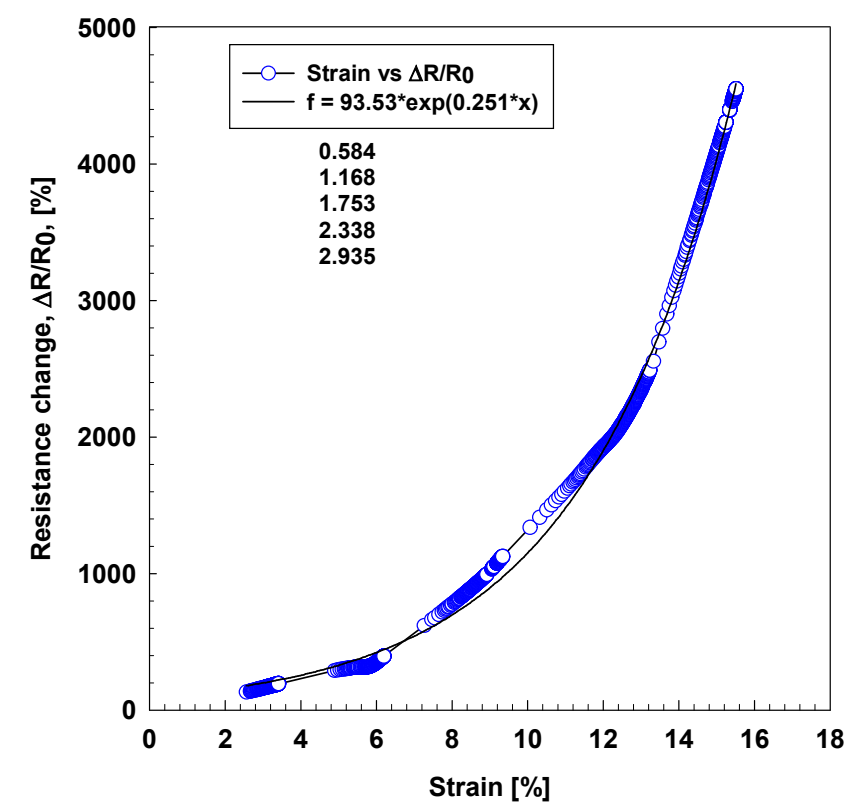

Fig. 4. Resistance change vs. strain for $\mathrm{EBC} / \mathrm{CF} 25 \mathrm{wt} \%$ composite in loading/unloading Figure 5 indicates the gauge factor for EBC/CF $25 \mathrm{wt} \%$. The gauge factor rise with strain values around 50 and at starting of deformation and growth as much as 300 at a strain of $16 \%$. This is a remarkable growth, which keeps $\mathrm{EBC} / \mathrm{CF}$ mixture within the variety of mixture of substances, and strain gauges with excellent sensitivity to the deformation of tensile. 


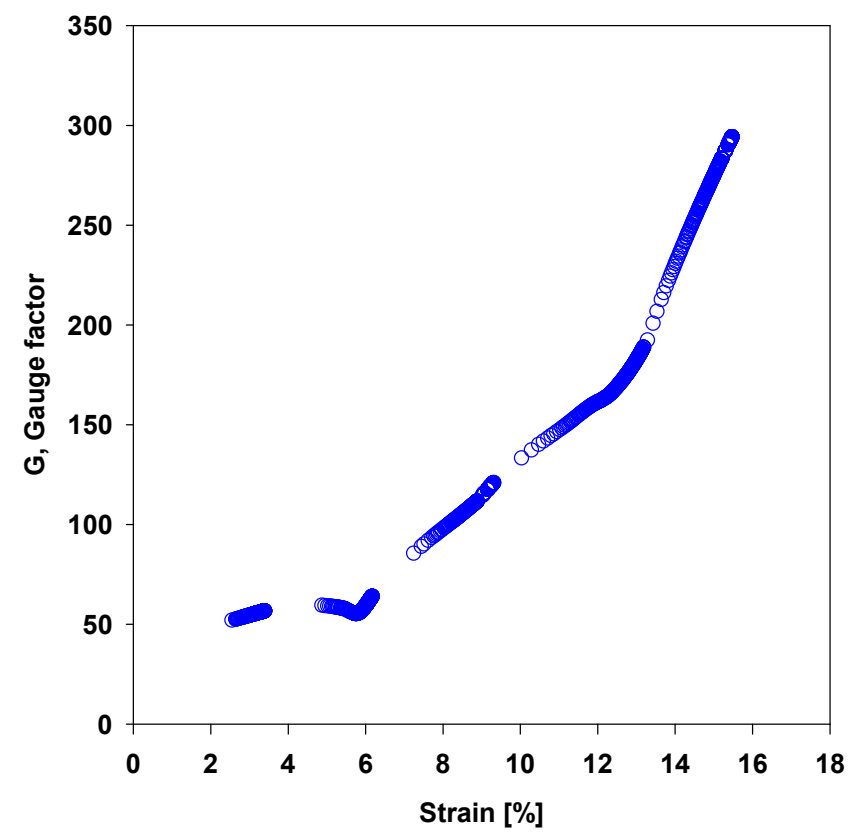

Fig. 5. Strain dependence of gauge factor GF EBC/CF $25 \mathrm{wt} \%$

\section{Thermal conductivity}

The dependence of temperature on time is described with the following equation.[10]

$$
-K \frac{d t}{d \tau}=\frac{S \lambda\left(T-T_{2}\right)}{\delta}+B\left(T-T_{2}\right)
$$

Where,

$$
\mathrm{T}_{2}=45^{\circ} \mathrm{C}
$$

$\mathrm{K}=$ the central brass cylinder heat capacity which is $317.5 \mathrm{~J} / \mathrm{k}$ in our work

$\mathrm{S}=$ sample area $\left(\mathrm{m}^{2}\right)$

$\lambda=$ thermal conductivity $\left(\mathrm{W} \mathrm{m}^{-2} \mathrm{~K}^{-1}\right)$

$\mathrm{T}=\mathrm{EBC} / \mathrm{CF}$ temperature $\left({ }^{\circ} \mathrm{C}\right)$

$\mathrm{T}_{1}=$ hollow brass cylinder temperature $25\left({ }^{\circ} \mathrm{C}\right)$

$\mathrm{T}_{2}=\mathrm{CBC}$ initial temperature $\left({ }^{\circ} \mathrm{C}\right)$

$\delta=$ specimen thickness $(\mathrm{m})$

$\mathrm{B}=$ coefficient accounting for a heat loss $\left(\mathrm{J} \mathrm{s}^{-1} \mathrm{~K}^{-1}\right)$

$\mathrm{s}=$ time $(\mathrm{s})$

$\mathrm{B}=$ calculated according to

$$
\mathrm{B}=\alpha \mathrm{S}_{\mathrm{Z}}
$$


Where

$\alpha=$ heat transfer coefficient $\left(\mathrm{W} \mathrm{m}^{-2} \mathrm{~K}^{-1}\right)$

$\mathrm{Sz}=$ heat loss area $\left(\mathrm{m}^{2}\right)$.

By solving Eq. 3:

$$
T=T_{1}-\left(T_{1}-T_{2}\right) * e^{\left|-\left(A_{1}-A_{2}\right) \tau\right|}(5)
$$

Where:

$$
\begin{aligned}
A_{1} & =\frac{S \lambda}{\delta K}(6) \\
A_{2} & =\frac{B}{K}(7)
\end{aligned}
$$

However, equation 5 can be simplified with exponential growth with three parameters as:

$$
y=y_{0}+a e^{(-b x)}
$$

The coefficient $b$ is obtained from the nonlinear regression.

The results of calculation of the thermal conductivities of EBC/CF is shown in Table 1 and Figure 6.

Table. 1. The thermal conductivity Parameters of EBC/CF

\begin{tabular}{|c|c|c|c|c|}
\hline $\mathrm{CF} \%$ & $\mathrm{~b}$ & $\mathrm{~A}_{1}$ & $\lambda\left(\mathrm{W} \mathrm{m}^{-2} \mathrm{~K}^{-}\right.$ & $\left.{ }^{1}\right)$ \\
\hline 0 & 0.0015611 & 0.0012981 & 0.1952 & 0.999976 \\
\hline 5 & 0.0019353 & 0.0016723 & 0.2266 & 0.999961 \\
\hline 10 & 0.0020541 & 0.00179114 & 0.2413 & 0.999968 \\
\hline 15 & 0.0021213 & 0.00185826 & 0.2477 & 0.999968 \\
\hline 20 & 0.0023160 & 0.002053 & 0.2635 & 0.999979 \\
\hline
\end{tabular}




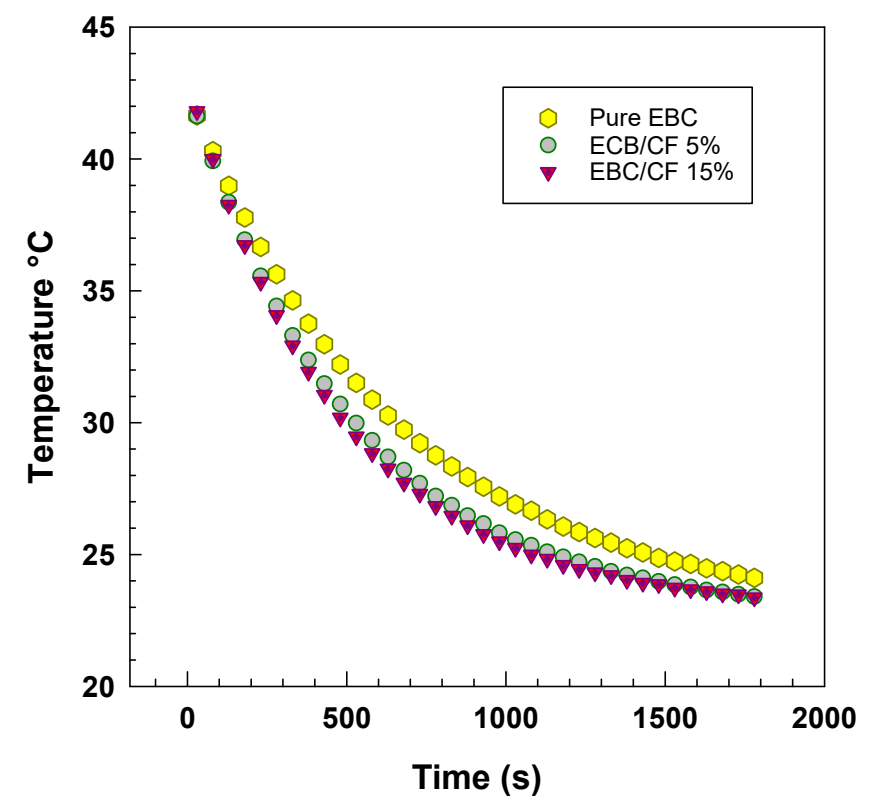

Fig. 6. Thermal conductivity measurement: temperature vs time for $\mathrm{EBC} / \mathrm{CF}$ for different concentration of carbon fiber content with the initial temperature of $45^{\circ} \mathrm{C}$

Figure 7 shows that the thermal conductivities of the EBC/CF composites increased with increasingCF. The highest measured thermal conductivity was $0.263 \mathrm{~W} \mathrm{~m}^{-1} \mathrm{~K}^{-1}$ for a $\mathrm{EBC} / \mathrm{CF} 20$ $\mathrm{wt} \%$ increase of $35 \%$ compared with pure EBC. 


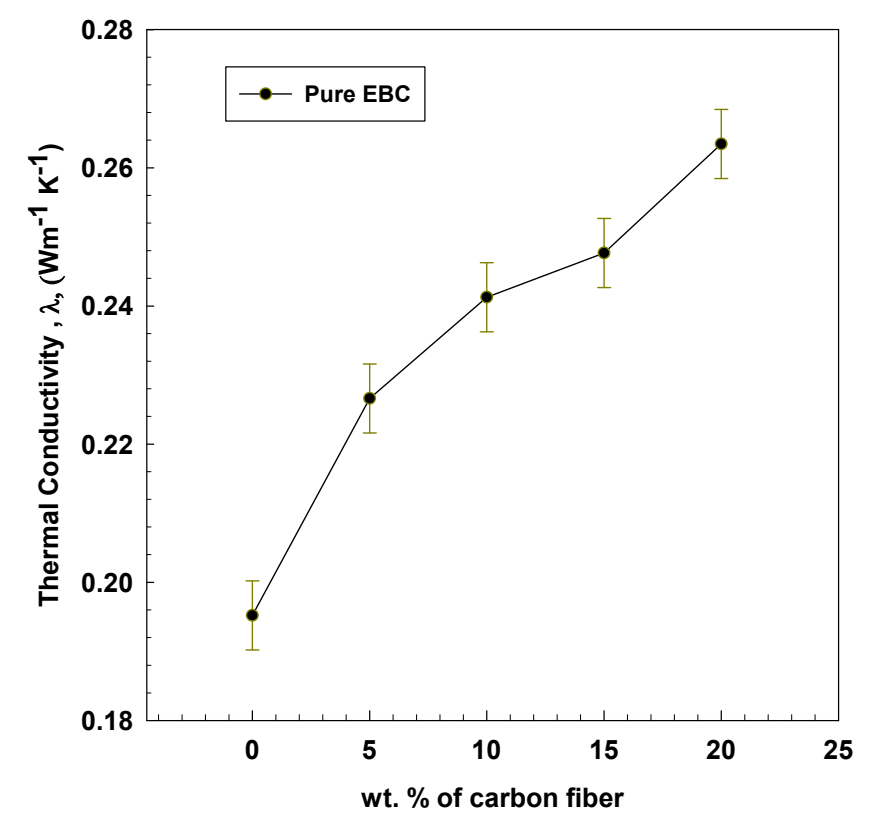

Fig. 7. Thermal conductivity as a function of carbon fiber content

Uniform distribution of CF had a large effect on the growth in thermal and electric conductivity. Since $\mathrm{CF}$ has a high conductivity for both heat and electricity, the loading of CF in EBC resulted in an increase in thermal and electric conductivities of the mixture [10,12].

\section{Conclusions}

$\mathrm{EBC} / \mathrm{CF}$ composites were prepared by the mixing the $\mathrm{EBC}$ with various levels of carbon fiber using a two roll-mill. The observations from optical microscopy indicated a fairly good dispersion of carbon fiber in the matrix. The electro-mechanical testing showed that straining of the composite led to a change of its macroscopic electrical resistance. The $\mathrm{EBC} / \mathrm{CF}$ strain sensitive composites were relatively sensitive to strain, and the changes were reversible. Therefore, the results indicate a good potential of the composites to be used as an electrical sensor for strain. The thermal conductivity of the mixtures indicated an increase of thermal conductivity with loading carbon fiber.

\section{Acknowledgement}

This was been supported by the Internal Grant Agency (IGA/FT/2017/007) of the Tomas Bata University in Zlin.

\section{Data availability}


The data that support the findings of this study are available from the corresponding author,

Yasin Hamid, upon reasonable request.

\section{REFERENCES}

1. Liang, J.C.; Ding, C.; Wei, Z.Y.; Sang, L.; Song, P.; Chen, G.Y.; Chang, Y.; Xu, J.T.; Zhang, W.X. Mechanical, morphology, and thermal properties of carbon fiber reinforced poly(butylene succinate) composites. Polym Composite 2015, 36, 1335-1345.

2. Imiela, M.; Anyszka, R.; Bielinski, D.M.; Pedzich, Z.; Zarzecka-Napierala, M.; Szumera, M. Effect of carbon fibers on thermal properties and mechanical strength of ceramizable composites based on silicone rubber. $J$ Therm Anal Calorim 2016, 124, 197-203.

3. Shen, Z.L.; Zhou, H.Y. Mechanical and electrical behavior of carbon fiber structural capacitors: Effects of delamination and interlaminar damage. Compos Struct 2017, 166, 38-48.

4. Slobodian, P.; Riha, P.; Saha, P. A highly-deformable composite composed of an entangled network of electrically-conductive carbon-nanotubes embedded in elastic polyurethane. Carbon 2012, 50, 3446-3453, doi:https://doi.org/10.1016/j.carbon.2012.03.008.

5. Slobodian, P.; Riha, P.; Olejnik, R.; Cvelbar, U.; Saha, P. Enhancing effect of KMnO4 oxidation of carbon nanotubes network embedded in elastic polyurethane on overall electro-mechanical properties of composite. Composites Science and Technology 2013, 81, 54-60, doi:10.1016/j.compscitech.2013.03.023.

6. Ibrahim, S.S.; Ayman, S.A. Electrical and optical properties of functionalized multiwalled carbon nanotubes/poly (3-octylthiophene)/polystyrene composites. J Thermoplast Compos 2013, 28, 225240, doi:10.1177/0892705713480517.

7. Slobodian, P.; Olejnik, R.; Matyas, J.; Babar, D.G. Improving sensitivity of the polyurethane/CNT laminate strain sensor by controlled mechanical preload. In Proceedings of IOP Conference Series: Materials Science and Engineering; p. 012022.

8. Liao, X.; Zhang, Z.; Kang, Z.; Gao, F.; Liao, Q.; Zhang, Y. Ultrasensitive and stretchable resistive strain sensors designed for wearable electronics. Materials Horizons 2017, 4, 502-510, doi:10.1039/c7mh00071e.

9. Li, X.; Levy, C.; Elaadil, L. Multiwalled carbon nanotube film for strain sensing. Nanotechnology 2008, $19,045501$.

10. Svoboda, P.; Theravalappil, R.; Poongavalappil, S.; Vilcakova, J.; Svobodova, D.; Mokrejs, P.; Blaha, A. A study on electrical and thermal conductivities of ethylene-octene copolymer/expandable graphite composites. Polymer Engineering \& Science 2012, 52, 1241-1249, doi:doi:10.1002/pen.22192.

11. Theravalappil, R.; Svoboda, P.; Vilcakova, J.; Poongavalappil, S.; Slobodian, P.; Svobodova, D. A comparative study on the electrical, thermal and mechanical properties of ethylene-octene copolymer based composites with carbon fillers. Mater Design 2014, 60, 458-467, doi:https://doi.org/10.1016/i.matdes.2014.04.029.

12. Ren, L.; Li, Q.; Lu, J.; Zeng, X.; Sun, R.; Wu, J.; Xu, J.-B.; Wong, C.-P. Enhanced thermal conductivity for Ag-deposited alumina sphere/epoxy resin composites through manipulating interfacial thermal resistance. Composites Part A: Applied Science and Manufacturing 2018, 107, 561-569, doi:https://doi.org/10.1016/i.compositesa.2018.02.010.

13. Zhou, B.; Luo, W.; Yang, J.; Duan, X.; Wen, Y.; Zhou, H.; Chen, R.; Shan, B. Thermal conductivity of aligned CNT/polymer composites using mesoscopic simulation. Composites Part A: Applied Science and Manufacturing 2016, 90, 410-416, doi:https://doi.org/10.1016/i.compositesa.2016.07.023.

14. Rahman, M.S. Evaluation of the precision of the modified Fitch method for thermal conductivity measurement of foods. J Food Eng 1991, 14, 71-82, doi:https://doi.org/10.1016/02608774(91)90054-V. 
15. Slobodian, P.; Riha, P.; Olejnik, R.; Matyas, J.; Machovsky, M. Pre-Strain Stimulation of ElectroMechanical Sensitivity of Carbon Nanotube Network/Polyurethane Composites. leee Sens J 2016, 16, 5898-5903.

16. Sanchez-Garcia, M.D.; Gimenez, E.; Lagaron, J.M. Morphology and barrier properties of solvent cast composites of thermoplastic biopolymers and purified cellulose fibers. Carbohyd Polym 2008, 71, 235-244, doi:https://doi.org/10.1016/j.carbpol.2007.05.041. 
